\title{
The popularisation of Positive Psychology as a defence Against BEHAVIOURAL COMPLEXITY IN RESEARCH AND ORGANISATIONS
}

Authors:

Frans Cilliers $^{1}$

Michelle May ${ }^{1}$

\section{Affiliations:}

${ }^{1}$ Department of Industrial and Organisational Psychology, University of South Africa, South Africa

Correspondence to: Frans Cilliers

email:

cillifvn@unisa.ac.za

Postal address:

Department of Industrial and Organisational

Pscyhology, PO Box 392,

Unisa 0003, South Africa

\section{Keywords:}

Listening post; Organisational

psychology; organisational wellness; qualitative research; systems psychodynamics

\section{Dates:}

Received: 09 Sept. 2009

Accepted: 19 May 2010

Published: 02 Dec. 2010

How to cite this article:

Cilliers, F., \& May, M. (2010). The popularisation of Positive Psychology as a defence against behavioural complexity in research and organisations. SA Journal of Industrial Psychology/SA Tydskrif vir Bedryfsielkunde, 36(2), Art. \#917, 10 pages. DOI: 10.4102/sajip.v36i2.917

This article is available at: http://www.sajip.co.za

(C) 2010. The Authors. Licensee: OpenJournals Publishing. This work is licensed under the Creative Commons Attribution License.

\section{ABSTRACT}

Orientation: Positive Psychology's focus on positive behaviour has resulted in research and organisational consultants to focus relatively more on positive behaviour, thus avoiding negative and often unconscious behaviour and its manifestations.

Research purpose: The aim of the study was to explore the systems psychodynamic nature of the manifesting defensive structures operating in Positive Psychology.

Motivation for the study: The study investigated the popularity of Positive Psychology amongst academics, students and organisational consultants and the tendency to avoid the complexity of the relatedness between positive and negative as part of the human condition.

Research design, approach and method: Qualitative research by means of a Listening Post was used, consisting of six psychologists in their roles as lecturers and organisational consultants. Thematic analyses led to the formulation of various working hypotheses, integrated into a research hypothesis.

Main findings: Four themes manifested - namely, the manifesting defence mechanisms, a reluctance to relinquish positive psychology as an object of hope, a need to guard against being too hasty in breaking down positive psychology and a need for a psychology that can engage us in a conversation about integrating the complexities of the human condition.

Practical/managerial implications: The findings were linked to Deo Strümpfer's work, indicating that Positive Psychology originated in early 20th century psychology, which is indeed not about simplification, but is imbedded in the complexity of various behavioural continua.

Contribution/value-add: Academics, students and organisational consultants are encouraged to revisit Strümpfer's work to ensure that this psychology is appreciated for its depth and quality.

\section{INTRODUCTION}

Since 2000, Positive Psychology gained momentum and quickly became popular amongst academics, students and organisational consultants in South Africa. From a philosophical perspective, Positive Psychology can be seen as a need to move away from focussing on the negative and to concentrate on positive behaviour (Seligman, 2003). Theoretically, Positive Psychology has developed to include a tremendous amount of behavioural constructs (Linley \& Joseph, 2004; Lopez \& Snyder, 2003; Snyder \& Lopez, 2002). Many of these constructs have already been psychometrically explicated (Wissing \& Van Eeden, 2002) while others are presently being researched in validity and reliability studies, as well as in organisational practice.

\section{Problem statement}

In our (the authors') roles as psychologists, academics, researchers and organisational consultants, we have been working in the fields of humanistic psychology, salutogenesis, fortigenesis, Positive Psychology and systems psychodynamics. Over time, we have become increasingly suspicious about the popularisation of Positive Psychology and the effect thereof in academia and organisations. This led to our analysis of the origins and nature of the theory and practice of Positive Psychology. Our analysis generated four questions from which a working hypothesis was formulated to guide this qualitative investigation.

\section{Is Positive Psychology a new psychology?}

In his role as chairperson of the American Psychological Association (APA) in 2000, Seligman (2003) referred to Positive Psychology as a new psychology, which led to references to him as the father of this movement (Linley, Joseph, Harrington \& Wood, 2006). It was as if Seligman had unilaterally given himself the authorisation to speak on behalf of his entire fraternity. He (Seligman, 2003; Snyder \& Lopez, 2002) strongly criticised Freud and psychodynamics as if to say that depth psychology principles were not applicable in (t)his new psychology and denied links between other 20th century theories and behavioural constructs. Lindley and Joseph (2004) criticised Seligman's view in their acknowledgment of the strong influence on Positive Psychology by Behaviourists (such as Bandura's work on self-efficacy) and Humanists (such as Maslow and Rogers' work on self-actualisation and optimal psychological functioning). They called the relationship between Humanistic Psychology and Positive Psychology contentious, but realised that the general principles underlying positive psychology (such as human potential, fulfilment, growth, optimal functioning) are not new. '[W]e have been here before' (Lindley \& Joseph, 2004, p. 365, they said, claiming that Maslow and Rogers need to be set on the Positive Psychology 
centre stage, because of their strong empirically based work Strümpfer (2005) also gave strong and convincing evidence that positive psychological thinking originated in philosophy and early 20th century psychology; Linley and Joseph (2004) refer to Positive Psychology's solid epistemological perspective based on humanistic and existential psychology. It seemed to us that although Positive Psychology is a new name, the origin of this field of study is theoretically rooted in many other 20th century psychologies and constructs.

\section{Is Positive Psychology a simplified psychology?}

Seligman (2003) and Csikszentmihalyi (in Snyder \& Lopez, 2002) referred to Positive Psychology as the study of positive behaviour in response to the 20th-century focus on negative behaviour alone. It was as if Positive Psychology was created as some kind of reaction (or defence) to this supposed inordinate focus on negative behaviour (see Blackman, 2004). Presently, Positive Psychology is defined in general as the study and optimisation of positive behaviours and feelings (Snyder \& Lopez, 2002). More detailed definitions are offered by specific theorists as they focus on their preferred behavioural construct such as emotional intelligence, resilience, strengths and positive emotions. It is as if the diversity of constructs has, up to the present time, restricted the synthesis of the research and the development of an integrated theory (see Linley \& Joseph, 2004). On the other hand, Strümpfer (Manganyi, Marais, Mauer \& Prinsloo, 1993), as a major contributor to this field, studied and cautioned us not to forget the complexity, systemic and in-depth thinking required in this work (Strümpfer, 2007). Linley and Joseph (2004) encapsulated Positive Psychology's fundamental assumptions about human nature, value assumptions, and focus on good empirical science. Our analysis of the nature of Positive Psychology gave strong evidence of a solid theoretical, empirical and epistemological foundation. Time will assist in the creation of a coherent and uniform definition. On the surface, some simplification manifested in the focus on positive, while denying negative, behavioural constructs.

Evidence of simplification was also found in our experience in practice. Academic research supervisors often suggest Positive Psychology themes to students who are unsure of research topics. The arguments in favour of taking up Positive Psychology include the easy research options that come with it, thereby avoiding complex research designs, as Positive Psychology is seen as involving linear thinking on the positivenegative continuum. Students are thus able to find a research title quicker and, because Positive Psychology is seen by some supervisors as being in vogue, they believe that research articles will be accepted more easily for journal publication. Perhaps, stimulated by academics, students often choose Positive Psychology as a field of research because of its assumed simplicity and popularity. It is as if they are attracted to the positive constructs such as happiness and optimism, which seems to create a sense of research as an easy and a pleasant experience.

\section{What happens with the negative in Positive Psychology?}

Theoretically, Positive Psychology rejects the negative as a category (Maddux, 2002, in Snyder \& Lopez, 2002) and accepts the positive and negative to represent a continuum. Yet, there is not a Positive Psychological theory to account for this position. Linley and Joseph (2004) declared this categorical distinction between positive and negative inappropriate, since they are both part of the same vein in human experience. At the same time, Linley, Joseph, Cooper, Harris and Meyer (2003) debunked criticism that called Positive Psychology Pollyanna theorising. They referred to the relatedness between posttraumatic stress and post-traumatic growth. Other examples of this relatedness of positive and negative are found in the research on engagement and burnout (Coetzer \& Rothmann, 2007; Van der Colff \& Rothmann, 2009), hope and despair, love and hate (Snyder \& Lopez, 2002). Although our analysis of the nature of Positive Psychology gave evidence of constructs that are studied in their positive-negative relatedness, in general there seems to be a denial of the negative which may create an illusion amongst academics, students and organisational consultants about what positive psychology is really about.

\section{Why is Positive Psychology simplified when applied to organisational work?}

Academic work on Positive Psychology, such as the Handbook of Positive Psychology (Snyder \& Lopez, 2002) and Golman's (1995) work on emotional intelligence serve as resources on the various positive psychology constructs with substantial theoretical and empirical evidence for their inclusion into the field. On the other hand, when the work is presented to organisational consultants, leadership and management, the content is popularised to the extent that its essence disappears. Examples are Seligman's (2003) work on authentic happiness and Golman's (2008) work on emotional intelligence in leadership. The above may explain what we often hear in practice when organisational consultants use Positive Psychology frameworks in the planning and conducting of their inputs - it is used 'because we are so tired of the negative attitude in teams', the conflicts, anger and aggression; 'anyway, management wants the people to be happy'. Although it is understandable that non-academic readers will not be interested in the depth of the theory, it is problematic when material is presented in a simplified (and almost infantilised) manner, creating false impressions about the seriousness and depth of the work.

\section{Working hypothesis}

From the above questions, the authors formulated the following working hypothesis (see Schafer, 2003): although the Positive Psychology literature presents a solid paradigm, theoretical depth and a clear epistemological perspective, in practice it is often seen as a new and immature psychology that serves as an escape from behavioural complexity in performing research and in organisational consulting. This response seems to be a defensive structure that seeks to maintain the fantasy of simplicity.

\section{The Systems Psychodynamic perspective}

Linley and Joseph (2004) suggested that our ethos in exploring the nature of Positive Psychology should not be driven by which questions fit out scientific methods, but what methods, scientific or otherwise, may be most appropriate for answering the questions of interest. Therefore, to explore the defensive and implied unconscious behaviour (see Campbell, 2007) in the above working hypothesis, the authors were led to using the systems psychodynamic stance as a research perspective. This is also known as the Tavistock approach (Miller, 1993) and the Group Relations stance (Brunner, Nutkevitch \& Sher, 2006). Theoretically, it incorporates Freudian (1921) systemic psychoanalysis, the work of Klein (1988) on family psychology, Ferenczi on object relations and Bertalanffy on systems thinking (Colman \& Bexton, 1975; Colman \& Geller, 1985; Cytrynbaum \& Noumair, 2004). As a research perspective, systems psychodynamics offers a depth-psychological organisational theory - a developmentally focused, psycho-educational process geared towards an understanding of the conscious and unconscious behaviour in the system (Armstrong, 2005; Campbell, 2007; Campbell \& Huffington, 2008; Huffington, Armstrong, Halton, Hoyle \& Pooley, 2004; Klein, 2005). The theory is based on five basic systemic behavioural assumptions, namely, dependency, fight/flight, pairing (Bion, 1961, 1970, 2003), me-ness (Turquet, 1974) and one-ness/we-ness (Lawrence, Bain \& Gould, 1996). The understanding of the basic assumptions are supported by the following specific systemic and dynamic behavioural constructs (Campbell \& Huffington, 2008; Cilliers, 2005; Cilliers \& Koortzen, 2005; Czander, 1993; Klein, 2005; Hirchhorn, 1993, 1997): 
- Anxiety: This is defined as the fear of future, acting as the driving force (dynamo) of the relationship and relatedness between subjects and objects.

- Task: This is the basic component of work and describes the primary task, indicating contained anxiety and diversions into off-task and anti-task behaviour as a defence against confusion and free-floating anxiety.

- Role: This describes the boundary around work and position, and between subjects and objects, where leadership is defined as managing the boundaries between what is inside and what is outside the role; how role dynamics differentiate between the normative, experiential and phenomenal.

- Authority: This is the formal and official right to perform the task, bestowed from above (the organisation, manager, leader), the side (colleagues), below (subordinates), and from within (self-authorisation).

- Boundaries: This includes concepts such as task, time and territory, which act as the space around, and between, parts of the system, keeping it safe and contained.

- Identity: This is the nature of the leader's role-behaviour and the branding, climate and culture of the organisational system.

\section{RESEARCH DESIGN}

The aim of the study was to explore the systems psychodynamic nature of the manifesting defensive structures operating in Positive Psychology against behavioural complexity in research and organisations.

The research design was qualitative and descriptive in nature (Brewerton \& Milward 2004; Camic, Rhodes \& Yardley, 2003). This implies that the researcher is interested in, and concerned about, socially relevant values and ethics, without being intimidated by power or status. The researcher asks the question, 'what is actually happening', while exploring by means of continual reflection and then describing the behaviour in the context of the theoretical framework - in this case, systems psychodynamics. In this research, a depth psychology perspective, which includes the manifestation of unconscious behaviour, was chosen in order to 'penetrate the illusion' (Higgs \& Smith, 2003, p. 67) that behaviour is only conscious. Thus, the reality of the experience of Positive Psychology as a comprising conscious and unconscious behaviour can be described.

\section{Research method \\ Data collection method}

A Listening Post was used. This method was developed by the Organisation for Promoting Understanding of Society (OPUS) (Stapley, 1996) for use in systems psychodynamic organisational research and consulting (Gould, Stapley \& Stein, 2001; Neumann, Keller \& Dawson-Shepherd, 1997). The method is based on the psychodynamic notion that by coming together in a group that represents a part of the whole (the micro system), the manifesting behavioural dynamics will reflect the nature and behaviour of the collective (the macro system) (see Wells, 1980) in its unconscious systemic relatedness. As an event, the Listening Post focuses on a specific matter that is to be understood. The design is unstructured, has no set theme beforehand and aims to provide participants with an opportunity to explore and understand the systems psychodynamic manifestations of the specific matter (Stapley, 2006; Stapley \& Collie, 2005). Participants are given a primary task, are encouraged to have a discourse by thinking, freeassociating and processing their experiences on the matter for one hour. In the next hour, they are encouraged to analyse the material that has emerged previously in terms of the conscious and unconscious dynamics and to formulate hypotheses about the matter (Dartington, 2000). The Listening Post consists of between six and 15 people. The nature and size of the event is structured such that a microcosm of the collective is created. The event is lead by a convenor who is informed about systems psychodynamics and who holds to the time boundaries firmly, introducing and closing the event. During the two separate mentioned hours, he or she joins the discourse in the role of member. The notion is that if the event is well planned, the space, time and task boundaries act as sufficient containment for the work. The content is tape-recorded and/or a scribe is used to produce a written account of the experience. The validity of the Listening Post is dependent on the convenor's ability to provide opportunities for participants to share their experiences in a contained space without judgement, memory or desire (Miller, 1993) and to manage the boundaries between the two roles of convenor and member.

\section{Research procedure}

The Listening Post was planned and 10 psychologists were invited; six accepted the invitation. The first author took up the role of convener (as explained above). The primary task of the Listening Post was stated as follows: 'In your role experience as a lecturer and/or a consulting psychologist, explore the identity of Positive Psychology in academia and organisations.' The event discourse was recorded by a scribe and analysed by both authors. The themes were electronically sent to all the participants with the request to read it through and comment on the trustworthiness of the data. Three participants responded, agreeing with the authors' interpretation of the data.

\section{Research participants}

The six participating psychologists (which included the convenor in role as participant) consisted of three Black females, two White females and one White male. They had Masters degrees and professional registration as Psychologists in the categories of clinical (3) and industrial (3). All participants were employed in positions of teaching and/or organisational consulting working in both fields of Systems Psychodynamics and Positive Psychology.

Thus, voluntary and convenient sampling was used (Henning, Van Rensburg \& Smit, 2004). This situation created a potential problem in terms of saturation (Terre Blanche, Durrheim \& Painter, 2006) because up to this point the sample was a given in the method. The researchers decided to accept the sample of eight with the probability to enlarge the sample in case the material was not rich enough for interpretation. As the data was seen as acceptable, the sample was not extended (by for example arranging another Listening Post).

\section{Data analysis}

A thematic analysis was used (Breverton \& Millward, 2004; Camic, Rhodes \& Yardley, 2003; De Vos, Strydom, Fouché \& Delport, 2002; Henning, Van Rensburg \& Smit, 2004). The purpose was to ascertain what themes manifested (Van Manen, 1990) in the Listening Post. The interpretation of the data was done through the application of the systems psychodynamic lens (Armstrong, 2005; Campbell, 2007; Gould, Stapley \& Stein, 2001; Huffington et al., 2004; Klein, 2005). Thus, the authors drew on their theoretical knowledge and subjective capacity to make sense of the nature of the identity of Positive Psychology. The sorting of the data resulted in themes abstracted into different working hypotheses, described as where 'the data is sorted in a variety of ways, resulting in a variety of interpretations' (Terre Blanche, Durrheim \& Painter, 2006, p. 342). Thereafter, the authors formulated the hypotheses that seemed to best describe the constructions presented by the data sources. In this research, the above description was extended to include Schafer's (2003) notion that the working hypothesis is a statement from a meta position that is true for the time being and can continuously be reassessed in the light of further evidence. The underlying belief is that insight is an unending process (Haslebo \& Nielson, 2000). 
The notion of trustworthiness was based on credibility and validity (Denzin, 1989; Denzin \& Lincoln, 1994). It is believed that the study had strong boundaries in its in-depth (psychological) description, which revealed the complexities of the variables and their interactions from a systemic and psychodynamic perspective. It is also believed, using the suggestions by Christians (2005) and Eisner (1998), that the enquiry yielded ethical and believable evidence. The Listening Post was conducted in a voluntary and confidential manner in terms of the participants' identity. Furthermore, the working hypotheses and interpretations were peer-reviewed by using both authors to study one another's work.

Following Appleton's (1995) suggestions, the scientific rigour of a research project lies in, (1) the detailed description of the research design, sample, data collection, analysis strategies and the outcome of the project, (2) involving the participants in the establishing of the trustworthiness of the themes, as well as (3) involving the readers of the work. As authors, we are thus appealing to the readers of the work in establishing the credibility of the research.

\section{FINDINGS AND DISCUSSION}

Based on the Listening Post data analysis, certain themes were identified which were integrated into the following four working hypothesis:

1. The manifesting of system domain, socially constructed, immature and neurotic defences.

2. A reluctance to relinquish Positive Psychology as an object of attachment to hope.

3. A need to guard against being hasty in breaking down Positive Psychology.

4. A need for a psychology which can engage us in a conversation about integrating the complexities of the human condition.

Working Hypothesis 1: System domain, socially constructed, immature and neurotic defences are used by Positive Psychology to defend against the complexity of human behaviour.

System domain defences (Bain, 1998) manifested in the realm of the old conversation in psychology about positivenegative, ease-disease and health-sickness behaviour. Positive Psychology is joining this conversation by taking up the position of focusing only on the positive and excluding the negative. Participant number 1 (P1) illustrated this by commenting that 'Positive Psychology contract positive stuff as a defence - where is the rest (i.e. negativity, emotional difficulties, frustrations)?' The position of focusing only on the positive and excluding the negative is further reinforced as illustrated by a comment of participant number 2 (P2),

If I reflect on my clients if you have issues do not address it. People have to put up with frustration avoidance, of dealing with difficult emotions and frustrations. We have to be good. Fighting is violating something. It is dysfunctional if you have the outburst. (Participant 2)

Socially constructed defences (Menzies, 1993) manifested in the argument that Positive Psychology wants to encourage the positive to ensure a harmonious and happy life without exploring the manifestation and experience of disharmony and unhappiness. Harris (2009) refers to this phenomenon as the 'happiness trap', which is based on the myth that happiness is the natural state for human beings, that mental suffering is abnormal, that getting rid of negative feelings creates a better life and that one should be able to control all thoughts and feelings. He suggests acceptance of what is as a way of exploring the real person.

Immature defences (Bion, 1961; 1970; Blackman, 2004, Vaillant, 1992) manifested as splitting, introjection, projection and projective identification.

\section{Splitting}

Splitting manifests where the conflict in psychology about positive (health) and negative (pathology) behaviour acts as a stressor. As a coping mechanism, Positive Psychology attaches to one emotional (the positive) side of the object psychology - what Klein (1998) would refer to as becoming the good breast - and detaches from the other (the negative, becoming the bad breast). This splitting creates polar opposites of good and bad, which means that the two parts of the object cannot integrate towards a Gestalt experience, or coherent image. The splitting of the own image often occurs alongside the splitting of the image of the other in the significant presence. For example, Positive Psychology splits off its negative part and then believes that other psychologies (such as psychoanalysis, systems psychodynamics) are splitting off their positive part. P2 reflected that 'Positive Psychology splits of its parts and which leads to polarisation.' On another occasion, P2 commented: 'Positive Psychology is the good angel, systems psychodynamic stance is the devil.' On another occasion, P2 stated that 'Positive psychology is the good breast, whereas systems psychodynamics is the bad breast, the crap, the unconscious, unclear, tentative, etcetra.' Developmentally, the splitting indicates that Positive Psychology is stuck in an immature dependency on the parental figure (e.g., psychology) (Bion, 1961, 1970). Hope-despair and engagement-burnout were mentioned as examples of positive-negative behavioural continua that Positive Psychology takes note of in its literature (Snyder \& Lopez, 2002). Where engagement-burnout seems to be theoretically researched and systemically integrated, the same can't be said of hope-despair.

\section{Introjection}

Introjection manifests where Positive Psychology has internalised the characteristics of the preferred and good object to establish closeness to and a constant presence with the positive. P1 stated that 'Positive Psychology contract [introject?] positive stuff as a defence - where is the rest, the other aspects of behaviour?' The manifestation of introjection is further illustrated by a participant (name not recorded) who stated that through its name, Positive Psychology has set up its identity. If name gives identity and if culture gives identity then what is positive becomes the identity and culture.' Taking in the positive diminishes the anxiety of the separation and tension arising from the ambivalence. This manifestation can be seen as how Positive Psychology has introjected its narcissism in a way to avoid experienced disappointment (see Freud, 1914).

\section{Projection}

Projection, as referred to by the participants, manifests where Positive Psychology has attributed the bad object (negative and pathological behaviour) to other psychologies (such as psychoanalysis and psychodynamics) in an attitude of prejudice, rejection and externalisation of the negative. P1 illustrated this by commenting that 'Positive Psychology contract positive stuff as a defence - where is the rest (i.e. negativity, emotional difficulties, frustrations)?' Participant number 4 (P4) also suggested 'that the power of Positive Psychology is to seduce you, you have to look good. In business, corporate world things are stated in terms of looking good, you cannot admit flaws in the system.' These 'flaws in the system' and 'the rest' must then be left (projected) elsewhere - perhaps into other psychologies and other parts of an organisation. Projection acts correlatively to introjection - the material of the projection is derived from the internalised configuration of the introjected (Armstrong, 2005).

\section{Projective identification}

Projective identification manifested in how Positive Psychology attributed the negative to the outside (other psychologies) so that the whole object (good and bad) is seen in a distorted light. 
Because the negative is unacceptable, it becomes projected onto the other as if it was really the other who originated the affect or impulse. The projector does not disavow what is projected, but remains fully aware of the affects or impulses and simply misattributes them as justifiable reactions to the other (Klein, 2005). Positive Psychology admits that the negative exists, but believes it to be a reaction to those same feelings and impulses in others. It is worth remembering that Positive Psychology had its own genesis in projected material (by calling itself positive), believing itself to be the just (rather than the unjust) victim. Bion $(1961,1970)$ mentioned the role of trust in projection. An interpretation would be that Positive Psychology is trusting the other psychologies to hold and contain its negative part with the wish or phantasy (an unconscious fantasy) that it may take it back later when the bad object is transformed or when Positive Psychology is ready to integrate the negative.

Neurotic defences (Blackman, 2004; Vaillant, 1992) manifested as idealisation, simplification and rationalisation.

\section{Idealisation}

In the split between positive and negative, Positive Psychology idealises the positive as the good and desired object. This is illustrated by participant number 4 (P4), who stated that the power of Positive Psychology is to seduce you, you have to look good.' This idealisation of the positive seems to be a projection of its narcissism (to relieve shame over its own inadequacy Armstrong, 2005) and to avoid the disappointment of realising the negative in the self.

\section{Denial}

Denial, as referred to or implied through several of the statements of the participants, manifested where Positive Psychology refuses to acknowledge the simultaneous existence of positive and negative behaviour as entities that are apparent to others - as if to actively say the bad reality of negative behaviour is not true (denial as a form of simplification - see Blackman, 2004). This is illustrated by a comment by P1, 'Positive psychology can be used as a denial (by consultants). I have an example of a coach and a coachee. The coach felt disillusioned by the coaching because the coachee wanted to give up.' This denial is blind to both the idealisation and emotional content of what is denied (Campbell, 2007), as illustrated by the rest of P1's comment:

'The coach (said to the coachee): hang in there, do not give up. P1: What would happen if you worked with the person?

Coach: What do you mean?

P1: Explore where the coachee is, otherwise it is a denial of ... I cannot go there.'

\section{Rationalisation}

Rationalisation manifested where Positive Psychology deals with the split between good and bad by offering explanations of why its truth is the only truth. The underlying dynamic could be about obsessing around its focus as a valid one. P2 states that Positive Psychology is used as a 'rationalisation, because positive psychology is the light at the end of the tunnel to defend against difficulties.'

In terms of defences, it seems that academics, students and organisational consultants are seduced by, and attached to, eros and libido, which are represented in positive and acceptable behaviour. The split indicates the denial of the role of thanatos and morbid, which are represented in negative and pathological toxic organisational behaviour (see Armstrong, 2005; Freud, 1921).

Working Hypothesis 2: There seems to be a reluctance to relinquish Positive Psychology as an object of hope.
In organisations there seems to be a tendency to privilege Positive Psychology at the expense of working with or dealing with pain, loss, suffering and dissatisfaction. In these situations, the positive emotions are in the centre. This privileging of Positive Psychology constructs, especially by managers in organisations and probably by consultants because they want to fulfil the requirements from the organisations or avoid the negativity in the system, is evident from the following two quotations. P4's first thoughts were about

an incident happening recently in a restructuring exercise during the communication session when line management gave feedback to a group. First the manager wants to express gratitude that people are handling it so positively with no emotional outbursts. Secondly, praising them for dealing with the difficult situation in a sensible manner and praising them for being resilient.

(Participant 4)

P3 recalled the following:

When a focus group was held at a company a week before engaging in industrial action, management was functioning at a totally different level than the employees. The manager said - we can fix this, the cup is half full already, things are positive. As much as he was trying to build on the positive, he was holding onto straw. She continued to say: You cannot tell people that all is ok when it is not. The reality works against the positive. If we want to survive we have to be real. I could feel volatile emotions that can't be ignored any more. For example, someone who has been there for 30 years, earns the same as someone who has started today. The door of the canteen has no handles. The chairs are so bad you cannot recycle it, it can only be burnt. At a group interview everyone was standing for 3 hours because no proper chairs are provided for employees. Yet, management is saying that things are ok.

(Participant 3)

Organisational consultants struggle to hear negative emotions and realities in a confrontational situation. It seems as if in these scenarios, those who do not want to hear and see are those who are in a more privileged financial position. In the described scenarios, positivity has become a tool in the hands of management to pacify employees and a way to ignore difficult emotions such as pain, rage and distress. It is also used as a tool to seduce those who are experiencing difficult emotions, to rather focus on their strengths and to some extent ignore their difficult emotions. $\mathrm{P} 4$ reflected that

in business and the corporate world, things are generally stated in terms of looking good - you cannot admit flaws in system. The power of the positive is seductive-you have to look good.

(Participant 4)

The reluctance to relinquish positivity by those in managerial positions seems to be pervasive and entrenched in organisations. P2 reflected that

this [the privileging of positivity by those in advantageous position] is a very pervasive and entrenched message. If I reflect on my clients - if you have issues, you do not address it. People put up with frustration and avoidance of dealing with difficult emotions. We have to be good. Fighting is violating something. It is dysfunctional if you have an outburst.

(Participant 2)

The question becomes: to what extent do organisational consultants use Positive Psychology to focus on the positive at the expense of holistically focussing on the real emotional experience of their clients in organisations? (see Czander, 1993). One participant gave an example of how a consultant, working from a positive psychology lens, wanted to ignore difficult emotions by using positivity to deny the difficult emotions experienced by a client. P1 noted the following:

The coach felt disillusioned by the coaching because the coachee wanted to give up. The coach said, hang in there, don't give up. Then I asked, what would happen if you worked with the person's 
flight of wanting to give up? The coach asked, what do I mean? It was as if coaching on negative behaviour such as flight or denial, or listening to the coachee's messiness was not even considered in this organisation.

(Participant 1)

More evidence was gathered of privileging Positive Psychology constructs in an attempt to avoid the difficult emotions and the 'messiness' of relationships in different contexts. Several comments from the participants illustrate this point: P4 gave examples of where 'in heated discussions, it is quickly said "let's take the discussion off-line"'. P2 called this 'repression - [the telephone company] has blocked the line.' P6 said that 'Positive Psychology seems to be obsessed with harmony while underneath - boil, boil, toil and trouble.' P1 then said that "'boil, toil and trouble" is the karma of harmony.'

However, ignoring the difficult emotions and the messiness of relationships in different contexts, does not resolve these aspects (Campbell \& Gronbaek, 2006). It merely splits the disavowed parts off and these parts will reappear to the detriment of those (organisations, clients and participants in research) who function in different contexts. Several comments from the participants pointed to this:

- P4: 'AAlthough organisations try to deny] the difficult situation or emotion in some point the group or organisation will repeat the moment of truth that it needs [to work with].'

- P2: 'Ignoring at your own peril the frustration and difficult emotions.' She vehemently continued that 'we cannot wish away hostile negative toxic emotion, only wanting to deal with good, though evil exists.

- Participant number 3 (P3) also said that in organisations things are happening underneath and a lot of sugar coating, a lot of things such as salaries.'

- P3, speaking to an executive in a company, asked him about how he felt if people insulted him during strike action by insulting his mother (in another language understood by several but not all). He said: 'I cannot see my mother's hair' (covered due to cultural reasons). 'But these people insult my mother and that breaks me'. The person eventually resigned. She continued to say about a similar situation that 'a person is attacked, but it is impossible to deal with the issue. Where does the legal come in?'

Another aspect revealed by the above statements is that people know about the disavowed (destructive) elements on a conscious level and the attempts by those in privileged positions to focus only on positivity. What is not available on the conscious level are the dynamics (both destructive and creative) underlying the disavowed destructive elements (Cytrynbaum \& Noumair, 2004). Furthermore the disavowed (destructive) elements will reappear in relationships and in the organisation if they are not attended to. This was illustrated by P2 who stated:

I went into a cognitive process where there was no need for the understanding of systemic issues or dynamics. I thought we were in a positive space, but the team refused to participate and I felt like I could not stay with the team. Then I realised that the cognitive process was not the agenda, but other issues. Then the anger, bitterness and tears came out.

(Participant 2)

This serves as example of how the official agenda defends against the real issue. The above suggests evidence that Positive Psychology and its constructs are ill-equipped to deal with or to make sense of the negativity. This is illustrated by $\mathrm{P} 1$, who commented that

Positive Psychology stands on its own and has well defined theory, constructs. But the organisation is rife with things that are far from normal, the organisation has its irrational dark side. [Positive Psychology] cannot stand on its own.

(Partcipant 1)

Given that proponents of Positive Psychology will probably not attend to these disavowed destructive elements, it is perhaps left to other psychologies to deal with these elements (Campbell \& Huffington, 2008). Thus, it appears that Positive Psychology claims hope, which leaves other psychologies to study only the negative aspects of behaviour such as despair (destruction). In this process, positivity is unwittingly projected onto Positive Psychology followed by the over-identification with this positivity. When Positive Psychology claims hope, it leaves other psychologies in general and systems psychodynamics in particular, to study only the negative aspects of behaviour (such as despair, destruction). P2 stated that 'Positive Psychology is the good angel, Systems Psychodynamics is the devil'. She continued to say that her 'suspicion is that all are the same [with regards to working with all the aspects of human behaviour], but we split and project so that we can continue fighting.'

From a philosophical perspective, Positive Psychology can be seen as a need to move away from focusing on the negative and to concentrate on positive behaviour (Seligman, 2003). The derivation of the positive is from the Latin ponere, meaning to put laws firmly and explicitly down, 'to admit to no question' and to be sure and convinced (Reader's Digest, 2009, p. 260-261).

The authors propose that what academics, students and organisational consultants need to work towards is that all psychological paradigms and theories contain the positive and the negative. The 'baby' must learn that it is the very same mother who is experienced as good can also be withholding and thus 'bad' (Klein, 1988). Like the baby, it needs to be learnt that it is the very same paradigm and theory that assists us in working with the positive and the negative, the good and the bad, the creative and the destructive of daily existence.

Working hypothesis 3: A need to guard against being hasty in breaking down Positive Psychology.

Based on several comments from the participants, sometimes with irritation and disregard, it seems evident that Positive Psychology can easily be regarded as a tool that can be used in organisations, but that the tool will not really deal with the underlying difficult issues in organisations. Participants seemed hasty in questioning the value of Positive Psychology and towards the end of the Listening Post, participants became suspicious in their thinking about what they have projected onto Positive Psychology - a container for the positive. One of the main points made was that as an organisational consultant faced by irrational and difficult emotions, Positive Psychology provides an opportunity to reflect on where and how to work with the positive aspects of the organisation. P3 reflected that 'toxicity in the system is not only bad, but that we need a vehicle to understand these parts.' P3 also stated that 'on a sub-conscious level it helps you to take the difficult and to carry through the difficult.' P4 stated that

The value of Positive Psychology is when you are in the position of actioning a way forward, if you are in a complex and stuck position and struggling, you can use Positive Psychology, you should not deny Positive Psychology.

(Participant 4)

P2 stated that

Positive Psychology has a place, but you first need to deal with the messiness. The path of healing is to confront anger and pain. When these are worked through, Positive Psychology is there to assist the healing further.

(Participant 2)

As authors we do not fully agree with this participant - part of healing would rather be to confront the anger, pain, and that as much as Positive Psychology can assist the healing further, it should also be able to deal with these difficult emotions and thus be part of the healing process (see Lawrence, 1999; Neumann et al., 1997).

Although the participants could explore the value of Positive Psychology, questions were raised about the contribution of 
TABLE 1

Constructs above and below the surface

\begin{tabular}{llllll}
\hline Above & $\begin{array}{l}\text { Happiness } \\
\text { Hedonic pleasure } \\
\text { Harmony } \\
\text { Gladness }\end{array}$ & $\begin{array}{l}\text { Resilience } \\
\text { Resource- } \\
\text { fullness }\end{array}$ & SOC & Gratitude & Self-confidence \\
Below & Eudamonic Happiness & Helpless & & \\
& Depression & Hopeless & & \\
& Discomfort & Distress & Narcissism & \\
& Depression & Envy & \\
& & & & Exploring transference and projection \\
& Conflict & & & \\
\hline
\end{tabular}

Positive Psychology in different areas such as globalisation, political and economic tensions amongst countries, the present economic meltdown, changes in South Africa, HIV/AIDS, to name but a few.

P3 suggested that 'maybe Positive Psychology remains hovering in the back as a boundary for what is going on.' When we work with pain, loss and suffering, we are aware of the positive hovering in the background as a container of the difficult process. In this situation the difficult emotions can be privileged or in the centre while the positive forms the background. In other situations Positive Psychology can be privileged, while difficult emotions such as despair, pain and loss can form the background. P2 commented that

at some level (the good and bad parts) are interlinked, what is in the background or foreground depends on whether pathology takes centre stage or whether positiveness takes centre stage. It is about what we privilege.

(Participant 2)

The psychology fraternity could use Gestalt psychology (Perls, Hefferline \& Goodman, 1986) as a transitional object to help the different of the positive-negative debate to integrate its parts. Working with the Gestalt of human behaviour implies bearing in mind the many aspects of human behaviour, knowing which aspects to work with at any given time, while always staying aware of what they are not working with and being ready to address these aspects as soon as it becomes necessary. This is illustrated by a comment from $\mathrm{P} 4$, who reflected that

Positive Psychology stands on its own through well defined theory and constructs. But organisations are rife with things that are far from normal, the organisation has its irrational dark side.

(Participant 4)

She continued to say that

Positive Psychology cannot stand on its own; it must be accompanied by a dark side. If you implement an affirmative intervention for victory, then crap hits and then you have to take the decision to go with the affirmative intervention of deal with [the difficult underlying emotions].

(Participant 4)

Based on the above, it needs to be acknowledged that other psychologies, including systems psychodynamics, also need to explore their contribution to the status quo, i.e. the projection of positivity into Positive Psychology and to own their disavowed parts (see Stapley, 2006). A more important question is: what will happen if Positive Psychology as an object within the psychology fraternity were to become aware of the to-and-froprojections of the positive and negative aspects of behaviour and could counter the projection of positivity. It is crucial for Positive Psychology to consider that it projects negativity and in so doing entrenching its identification with positivity. Although we have to work against the disregard for the value of Positive Psychology, it is also evident that Positive Psychology opens itself up for such criticism by not working vigorously with both the positive and negative aspects of human behaviour. Consequently, Positive Psychology can give back the projections (Campbell, 2007) from other psychologies by not just paying

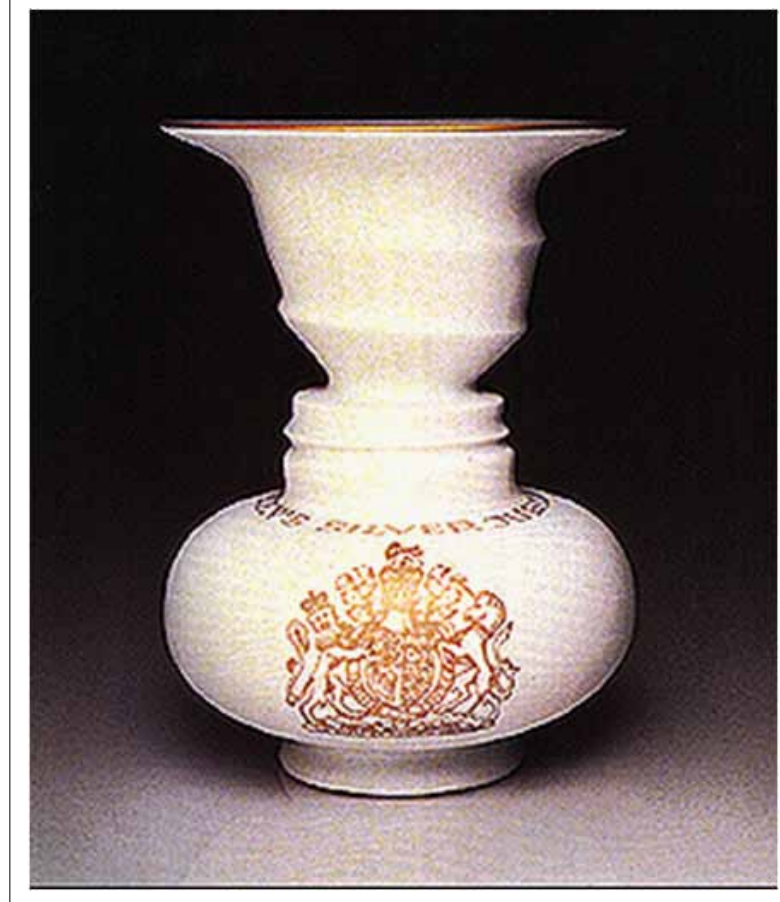

Source: http://www.cg.tuwien.ac.at/courses/Seminar/WS2005/index.php/Optische_ Taeuschungen

FIGURE 1

Figure and ground

lip service to the idea that they need to work with the negative aspect of human behaviour, but integrate more vigorously the complexities of the human condition.

Working hypothesis 4: There seems to be a need for a psychology which can engage us in a conversation about integrating the complexities of the human condition.

Participants asked questions about what lies below the surface when working with Positive Psychology (see Huffington et al., 2004; Stapley, 2006). P2 indicated that she would be interested in seeing the iceberg of Positive Psychology.

Based on this comment, the authors have developed a proposal about what could be below the surface of Positive Psychology constructs. This proposal is illustrated by exploring the role of hedonic and eudaimonic happiness (Strümpfer, 2003) in Positive Psychology. Hedonic happiness, which refers to the individual's subjectively experienced simple pleasure and the avoidance of pain, is placed above the surface (see Seligman's (2003) reference to the hedonic treadmill). Eudaimonic happiness includes enjoyment and even a struggle with difficulties to attain optimal experiences and functioning in all spheres of life, and is placed below the surface. The good life or 'eudaimonic happiness', as opposed to hedonic pleasure, refers to effort that a person exerts to achieve his or her optimal potential. Eudaimonia as a construct describes optimal experiences or happiness that 


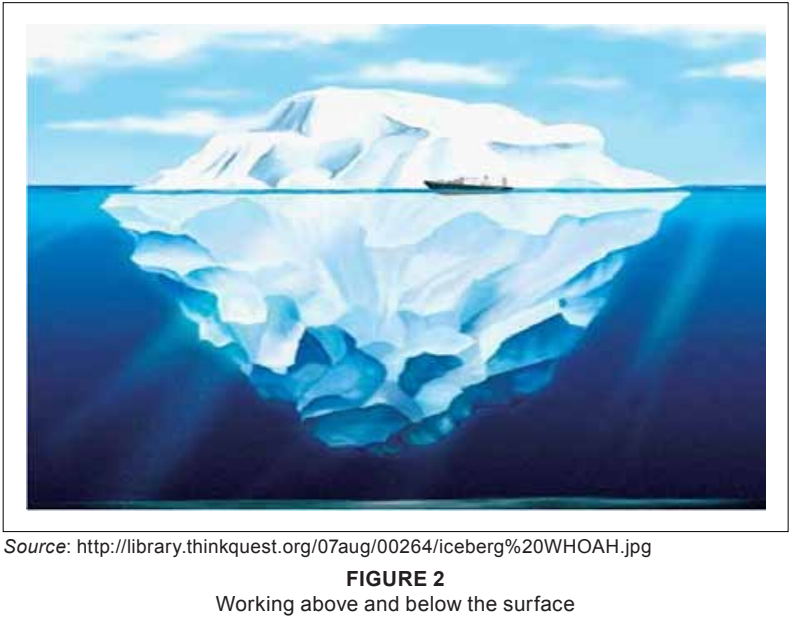

incorporates aspects of experiences beyond mere enjoyment (Strümpfer, 2003). Although eudaimonic happiness focuses on positivity, it more readily allows for the exploration of difficult emotions in the context of personal, optimal development.

Table 1 does not serve as an extensive proposal about what behaviours could be above and below the surface. Rather, the authors consider it an invitation for those working within Positive Psychology to think about what sides of the Positive Psychology constructs they are not working with, i.e. projecting into other psychologies, paradigms and theories (such as systems psychodynamics). This also suggests that Positive Psychology may need to take back its projections that it has left with other disciplines in general, and with Systems Psychodynamics in particular. It will also enable proponents of Positive Psychology to work more actively with behavioural aspects below the surface using the iceberg metaphor Furthermore, we realise that this is a metaphor developed from a Systems Psychodynamics lens and it is crucial that proponents of Positive Psychology should develop their own metaphor for exploring difficult emotions that lie below the surface.

\section{Formulating the research hypothesis}

The findings suggest that the identity of Positive Psychology is characterised by dependency and its accompanied immature and neurotic defences. This leads to Positive Psychology becoming known and utilised as a convenient and simplified psychology. It is interpreted that Positive Psychology represents and acts as a container for simplification in the teaching and practising of psychology. Positivity (in the here-and-now) and hope (in the future) is projected by managers, practitioners and researchers into Positive Psychology as a container through the use of immature, neurotic and system domain defences. This is done at the expense of denying negative, difficult emotions, represented by negativity and despair. The proponents of Positive Psychology seem so strongly invested in positivity that they tend to privilege Positive Psychology at the expense of working with and dealing with all aspects of human behaviour. As much as the proponents of Positive Psychology project these disavowed parts into other paradigms and theories, the others project their disavowed parts into Positive Psychology. Through this awareness - a willingness by Positive Psychology to work vigorously with all the aspects of human behaviour - it will be possible for the psychology fraternity to work more readily with the contributions of Positive Psychology. Thus the challenge for academics, students and organisational consultants working in both Positive Psychology and other psychologies, becomes the integration of the complexity of human behaviour.

The following research hypothesis was formulated. Although there is overwhelming literature evidence of the complexity within the boundary of Positive Psychology theory and practice, the conflict between positive and negative led to the de-authorisation of Positive Psychology towards putting it in a role of the simplified and easy field of study. This defensive structure of split between positive and negative and living in the projected and denied state, led to different psychological paradigms being robbed of its Gestalt and integration of behavioural complexity.

\section{Conclusion}

\section{Final thoughts}

These findings are reminders of how Strümpfer conceptualised Positive Psychology as both paradigm and theory with its various constructs. His work is based on many years of interest in, and intrigue towards, Positive Psychology (Manganyi, Marais, Mauer \& Prinsloo, 1993), although he framed his contributions within different paradigms, namely, salutogenesis, fortigenesis and psychofortology (Strümpfer, 1990, 1992, 1995).

In terms of origin, Strümpfer (2005) scientifically explored how Positive Psychology is imbedded in the work of the 20th century psychology giants who worked within analytical psychology, behaviourism, humanistic and existential psychology. Philosophically, he contextualised the popularity of Positive Psychology as a product of the present Zeitgeist and how this explains the mushrooming of positive behavioural constructs and the excitement around studying positive behaviour.

In terms of complexity of thinking, Strümpfer's (1990) work on salutogenesis served as a platform to focus not only on positive aspects of behaviour, but to work with the complex integration of positive and negative. Examples are the description of the ease-disease continuum and the role of generalised resistance resources (GRRs). He (Strümpfer, 1993) put the study of wellness in the realm of complex and dynamic systems, realising that wellness is about adaptation as well as mal-adaptation. In all his work, Strümpfer (see 2005, 2007) cautioned against a simplified, linear, mechanistic, one-sided and cause-and-effect view in research, psychology in general as well as in Positive Psychology, since they are most likely to offer an insufficient basis for understanding. He illustrated how the in-depth understanding and appreciation of Positive Psychology utilises a 'both-and'/systemic thinking, based on two continua, namely, mental/psychological ill-health and mental/psychological wellness. He suggested using a systems psychodynamic perspective to include contextual factors such as personal and social variables, timing and life-course variables, sequencing and the compass of impacting variables. He further suggested that research interests should be broadened to the investigation of complex phenomena using quantitative and qualitative investigations.

Antonovsky, the founder of salutogenesis, introduced the concept based on the Latin word salus (meaning 'health') and the Greek word genesis (which means 'origins') (Strümpfer, 1990). In the South African literature, six salutogenic constructs have been studied quite extensively, viz sense of coherence (the core construct of the salutogenesis model), locus of control, self-efficacy, hardiness, potency and learned resourcefulness (Strümpfer, 1990; Coetzee \& Cilliers, 2001). Strümpfer (1995) argued for the broadening of salutogenesis to include the sources of strengths. He introduced the concept of 'fortigenesis' - meaning the origins of psychological health and strength. In South Africa the field of psychofortology was suggested by Wissing and Van Eeden in 1997 to refer to the same study field as positive psychology (Strümpfer, 2005). Against this backdrop, Strümpfer (1990) held that pathogenesis compared to these paradigms, salutogenesis in particular, do different and complementary 'work' in psychology. Strümpfer (1990) based his work in the three paradigms, which provide psychologists with the challenge of understanding the how and where people find the strength to remain healthy in the face of stressful life events. This includes experiencing the stress, emotional difficulties, negativity and destructive feelings associated with all life events. 
In the organisational context, Strümpfer (2007) stressed the point that Industrial Psychologists should not forget that Industrial/Organisational Psychology is psychology. He encourages for psychology in organisations to contemplate with deep consideration for the human condition and to be inspired towards caritas (loving kindness), dynamic thinking and creation as scientists and professionals.

The authors honour Strümpfer's role, modelling and diligence in establishing Positive Psychology as a rich, deep and systemic view on all behaviour from a positive perspective. This includes the way in which he used every possible opportunity to inform, enlighten and warn fellow psychologists and academics to take the study of psychology in general, and its positive constructs, seriously.

It is suggested that academics and practitioners become aware of the tendency within Positive Psychology to simplify, avoid and deny its complexity. P2 illustrates this clearly by stating that 'Positive Psychology hides its complexity, we hide the complexity of Positive Psychology.' As a 'new' paradigm, we may be witnessing the early identity establishment phase known to be difficult and stormy (and filled with counterdependence - see Cilliers \& Koortzen, 2005). At the same time this awareness, needs to include the real origins of Positive Psychology in well established behavioural views.

It remains the responsibility of academics and practitioners to ensure that the paradigm is used in a responsible and ethical manner. Strümpfer (1993) referred to the human specialists to be the conscience in the organisation and to ensure that all human inputs are approached with wisdom, responsibility and ethos. This requires official and ongoing training and development in psychology with specialisation in Organisational Psychology.

Finally, it is suggested that academics, students and organisational consultants within the field of Positive Psychology, revisit Strümpfer's work to ensure that this psychology is appreciated for the depth and quality it deserves. Based on the way the authors know him and read his work, Strümpfer would encourage us to stay self-reflective in our practice of psychology, mindful of the fundamental assumptions, to explicate the value proposition of our work and to function in an integrative manner in our approach and applications of Positive Psychology.

\section{REFERENCES}

Appleton, J.N. (1995). Analysing qualitative interview data: Addressing issues of validity and reliability. Journal of Advanced Nursing, 22, 993-997.

Armstrong, D. (2005). Organisation in the mind. Psychoanalysis, group relations and organisational consultancy. London: Karnac.

Bain, A. (1998). Social defences against organisational learning. Human Relations, 51(3), 413-429.

Bion, W.R. (1961). Experiences in groups. London: Tavistock.

Bion, W.R. (1970). Attention and interpretation. London: Tavistock.

Bion, W.R. (2003). Learning from experience. London: Karnac.

Blackman, J.S. (2004). 101 Defences. How the mind shields itself. New York: Brunner-Routledge.

Breverton, P., \& Millward, L. (2004). Organisational research methods. A guide for students and researchers. London: Sage.

Brunner, L.D., Nutkevitch, A., \& Sher, M. (2006). Group relations conferences. Reviewing and exploring theory, design, role-taking and application. London: Karnac.

Camic, P.M., Rhodes, J.E., \& Yardley, L. (2003). Qualitative research in Psychology. Washington: American Psychological Association.

Campbell, D. (2007). The socially constructed organisation. London: Karnac.

Campbell, D., \& Gronbaek, M. (2006). Taking positions in the organisation. London: Karnac.
Campbell, D., \& Huffington, C. (2008). Organisations connected. A handbook of systemic consultation. London: Karnac.

Christians, C.G. (2005). Ethics and politics in qualitative research. In N.K. Denzin \& Y.S. Lincoln, (Eds.), The sage handbook of qualitative research (3rd edn.). pp. 139-164. London: Sage Publications.

Cilliers, F. (2005). Executive coaching experiences. A systems psychodynamic perspective. South African Journal of Industrial Psychology, 31(3), 23-30.

Cilliers, F., \& Koortzen, P. (2005). Conflict in groups. The CIBART model. HR Future, October, 52-53.

Coetzee, S., \& Cilliers, F. (2001). Psychofortology: Explaining coping behaviour in organisations. The Industrial-Organisational Psychologist, 38(4), 62-68.

Coetzer, W.J., \& Rothmann, S. (2007). A psychometric evaluation of measures of affective well-being in an insurance company. South African Journal of Industrial Psychology, 33(2), $7-15$.

Colman, A.D., \& Bexton, W.H. (1975). Group relations reader 1. Jupiter: The A.K. Rice Institute.

Colman, A.D., \& Geller, M.H. (1985). Group relations reader 2. Jupiter: The A.K. Rice Institute.

Cytrynbaum, S., \& Noumair, A. (2004). Group relations reader 3. Jupiter: A.K. Rice.

Czander, W.M. (1993). The psychodynamics of work and organizations. New York: Guilford.

Dartington, T. (2000). The pre-occupation of the citizen - reflections from the OPUS Listening Posts. Organisational and Social Dynamics, 1, 94-112.

De Vos, A.S., Strydom, H., Fouche, C.B., \& Delport, C.S.L. (2002). Research at grass roots. For the social sciences and human service professions. Pretoria: Van Schaik.

Denzin, N.K. (1989). The research act. Englewood Cliffs: Prentice Hall.

Denzin, N.K., \& Lincoln, Y.S. (1994). Handbook of qualitative research. Thousand Oaks: Sage.

Eisner, E.W. (1998). The enlightened eye: Qualitative inquiry and the enhancement of educational practice. Toronto: Macmillan.

Freud, S. (1914). On narcissism. An introduction. Standard Edition, 14, 73-102.

Freud, S. (1921). Group psychology and the analysis of the ego. Complete works of Sigmund Freud. London: Hogarth.

Golman, D. (1995). Emotional intelligence. New York: Bantam.

Golman. D. (2002). The new leaders. Transforming the art of leadership into the science of results. London: Sphere.

Gould, L.J., Stapley, L.F., \& Stein, M. (2001). The systems psychodynamics of organisations. London: Karnac.

Harris, R. (2009). Psychology: Positive thinking debunked. New York: Trumpeter.

Haslebo, G., \& Nielson, S. (2000). Systems and meaning. Consulting in organisations. London: Karnac.

Henning, E., Van Rensburg, W., \& Smit, B. (2004). Finding your way in qualitative research. Pretoria: Van Schaik.

Higgs, P., \& Smith, J. (2003). Rethinking truth. Landsdown: Juta.

Hirschhorn, L. (1993). The workplace within: Psychodynamics of organizational life. Cambridge: MIT.

Hirschhorn, L. (1997). Reworking authority. Leading and following in the post-modern organisation. London: MIT.

Huffington, C., Armstrong, A., Halton, W., Hoyle, L., \& Pooley, J. (2004). Working below the surface. The emotional life of contemporary organisations. London: Karnac.

Klein, L. (2005). Working across the gap. The practice of social science in organisations. London: Karnac

Klein, M. (1988). Envy and gratitude and other works 1946-1963. London: Hogarth.

Lawrence, W.G. (1999). Exploring individual and organisational boundaries. A Tavistock open systems approach. London: Karnac.

Lawrence, W.G., Bain, A., \& Gould, L. (1996). The fifth basic assumption. London: Tavistock.

Linley, P.A., \& Joseph, S. (2004). Positive psychology in practice. New York: John Wiley. 
Linley, P.A., Joseph, S., Cooper, R., Harris, S., \& Meyer, C. (2003). Positive and negative changes following vicarious exposure to the September 11 terrorist attacks. Journal of Traumatic Stress, 16, 481-485.

Linley, P.A., Joseph, S., Harrington, S., \& Wood, A.M. (2006). Positive psychology: Past, present, and (possible) future. The Journal of Positive Psychology, 1(1), 3-16.

Lopez, S.J., \& Snyder, C.R. (2003). Positive psychology assessment. Washington: American Psychological Association.

Manganyi, N.C., Marais, H.C., Mauer K.F., \& Prinsloo, R.J. (1993). A festschrift for Deodandus Strümpfer. A dissident among patriots. Pretoria: HSRC.

Menzies, I.E.P. (1993). The functioning of social systems as a defence against anxiety. London: Tavistock.

Miller, E.J. (1993). From dependency to autonomy: Studies in organization and change. London: Free Association.

Neumann, J.E., Keller, K., \& Dawson-Shepherd, A. (1997). Developing organisational consultancy. London: Routledge.

Perls, F.S., Hefferline, R.F., \& Goodman, P. (1986). Gestalt therapy. London: Souvenier.

Reader's Digest. (2009). The origins of words and phrases. Ultimo: Reader's Digest.

Schafer, R. (2003). Insight and interpretation. The essential tools of psychoanalysis. London: Karnac.

Seligman, M.E.P. (2003). Authentic happiness. London: Nicholas Brealey.

Snyder C.R., \& Lopez, A.J. (2002). Handbook of positive psychology. New York: Oxford.

Stapley, L.F. (1996). The personality of the organisation. A psychodynamic explanation of culture and change. London: Free Association.

Stapley, L.F. (2006). Individuals, groups and organisations beneath the surface. London: Karnac.

Stapley, L.F., \& Collie, A. (2005). Global dynamics at the dawn of 2005. Organizational and Social Dynamics, 5(1),111-133.

Strümpfer, D.J.W. (1990). Salutogenesis: A new paradigm. South African Journal of Psychology, 20(4), 265-276.

Strümpfer, D.J.W. (1992). Psychological strengths as point of departure: Fortigenesis. Address on occasion of receiving PASA award, annual congress, psychological Association of South Africa, Stellenbosch. 1 October 1992.
Strümpfer, D.J.W. (1993). Fie on 'survival of the fittest': A more humane view of people in organisations. In N.C. Manganyi, H.C. Marais, K.F. Mauer \& R.J. Prinsloo (Eds.) A festschrift for Deodandus Strümpfer. A dissident among patriots (n.p.). Pretoria: HSRC.

Strümpfer, D.J.W. (1995). The origins of health and strength: From 'salutogenesis' to 'fortigenesis'. South African Journal of Psychology, 25(2), 81-89.

Strümpfer, D.J.W. (2003). Resilience and burnout: A stitch that could save nine. South African Journal of Psychology, 33(2), 69-79.

Strümpfer, D.J.W. (2005). Standing on the shoulders of giants: Notes on early positive psychology (Psychofortology). South African Journal of Psychology, 35(1), 21-45.

Strümpfer, D.J.W. (2007). Lest we forget that Industrial and organisational psychology is psychology. South African Journal of Industrial Psychology, 33(1), 1-7.

Terre Blanche, M., Durrheim, K., \& Painter, D. (2006). Research in practice. Applied methods for the social sciences. Cape Town: UCT Press.

Turquet, P.M. (1974). Leadership - the individual in the group. In G.S. Gibbard, J.J. Hartman \& R.D. Mann (Eds.), Analysis of groups (n.p.). San Francisco: Jossey-Bass.

Vaillant, G. (1992). Ego mechanisms of defence: A guide for clinicians and researchers. Washinghton: American Psychiatric Press.

Van der Colff, J.J., \& Rothmann, S. (2009). Occupational stress, sense of coherence, coping, burnout and work engagement of registered nurses in South Africa. South African Journal for Industrial Psychology, 35(1), Art. \#423, 10 pages.

Van Manen, M. (1990). Researching lived experience. Toronto: State University of New York.

Wells, L. (1980). The group-as-a-whole: A systemic socio-analytical perspective on interpersonal and group relations. In C.P. Alderfer \& C.L. Cooper (Eds.), Advances in experiential social processes, 2, 165198.

Wissing, M.P., \& Van Eeden, E. (2002). Empirical clarification of the nature of psychological well-being. South African Journal of Psychology, 32(1), 32-44. 